\title{
Efeito do teor de gordura nas características químicas e sensoriais de embutido fermentado de carne de caprinos $^{(1)}$
}

\author{
Renata Tieko Nassu(2), Lireny Aparecida Guaraldo Gonçalves ${ }^{(3)}$ e Frederico José Beserra(4)
}

\begin{abstract}
Resumo - O objetivo deste trabalho foi verificar o efeito da adição de diferentes teores de gordura $(5,10$ e 20\%) no processamento, características químicas e aceitação sensorial do embutido fermentado de carne de caprinos. Durante o processamento, foram monitorados o $\mathrm{pH}$ e a atividade da água. Nos produtos finais, foram determinadas a umidade, a proteína e a gordura, bem como a aceitação sensorial, por meio de escala hedônica. As médias finais de $\mathrm{pH}$ e a atividade de água, na faixa de 5,07 a 5,14 e 0,897 a 0,923, respectivamente, não apresentaram diferença significativa $(P>0,05)$ entre os tratamentos. Os atributos sensoriais estudados não apresentaram diferenças significativas $(\mathrm{P}>0,05)$. As diferentes porcentagens de gordura utilizadas no processamento de embutido fermentado de carne de caprinos não afetaram significativamente seu processamento e aceitação sensorial. Em vista do baixo teor de gordura na carne de caprinos, considerou-se como mais adequadas formulações contendo $10 \mathrm{a}$ $20 \%$ de gordura.
\end{abstract}

Termos para indexação: produtos cárneos, lingüiças, teor de lipídios, propriedades organolépticas.

\section{Effect of fat level in chemical and sensory characteristics of goat meat fermented sausage}

\begin{abstract}
The objective of this study was to verify the effect of the addition of different fat contents $(5,10$ and 20\%) in the processing, chemical characteristics and sensory acceptance of a goat meat fermented sausage. During processing, $\mathrm{pH}$ and water activity were measured. Moisture, protein and fat contents were determined in final products, as well as sensory acceptance by hedonic scale. Final average values of $\mathrm{pH}$ and water activity, which ranged from 5.07 to 5.14 and 0.897 to 0.923 respectively, showed no significant difference $(\mathrm{P}>0.05)$ among any of all treatments. There were no significant differences $(\mathrm{P}>0.05)$ for any of all measured sensory attributes. No different percentage of fat in manufacturing of goat meat fermented sausage significantly affected its processing and sensory acceptance. Due to low fat content in goat meat, 10 to $20 \%$ of fat level were considered as the most adequate.
\end{abstract}

Index terms: meat products, sausages, lipid contents, organoleptic properties.

\section{Introdução}

Atualmente, doenças cardiovasculares, hipertensão, diabetes e obesidade são associadas ao consu-

(1) Aceito para publicação em 11 de setembro de 2001 .

Extraído da tese de doutorado apresentada pelo primeiro autor à Universidade Estadual de Campinas (Unicamp), Fac. de Engenharia de Alimentos (FEA), Campinas, SP.

(2) Embrapa-Centro Nacional de Pesquisa de Agroindústria Tropical, Rua Dra. Sara Mesquita, 2270, Pici, CEP 60511-110 Fortaleza, CE. E-mail: renata@cnpat.embrapa.br

(3) Unicamp, FEA, Caixa Postal 6091, CEP 13081-970 Campinas, SP. E-mail: lireny@fea.unicamp.br

(4) Universidade Federal do Ceará, Dep. de Tecnologia de Alimentos, Campus do Pici, Caixa Postal 12168, CEP 60356-000 Fortaleza, CE. E-mail: beserra@ufc.br mo de alimentos com alto teor de calorias, principalmente ricas em carboidratos ou gorduras.

Em produtos cárneos, a gordura é essencial ao sabor e textura, portanto a sua redução pode afetar a aceitabilidade do produto (Mittal \& Barbut, 1994). A tentativa de reduzir o teor de calorias é reportada por vários autores, como a substituição de gordura por carne magra e a utilização de proteínas de soja, de gomas como xantana, carragena, locusta e de carboximetilcelulose (Sofos \& Allen, 1977; Wallingford \& Labuza, 1983; Foegeding \& Ramsey, 1986). São necessárias modificações na composição e natureza de produtos com baixo teor de gordura. Essas modificações afetam os atributos de qualidade, que dependem das características da matriz formada. Tal matriz varia de acordo com a porcentagem 
de gordura e de proteína presente na matéria-prima utilizada (Carballo et al., 1995).

A produção de caprinos no Nordeste brasileiro é considerada como importante atividade econômica. Cortes nobres alcançam altos preços, ao passo que o restante apresenta baixa aceitação pelos consumidores e pouco valor comercial. O processamento de um embutido fermentado de carne caprina é uma alternativa para agregar valor a este produto. Como a carne de caprinos tem um baixo teor de gordura, em torno de 2 a $3 \%$, há necessidade de se determinar a porcentagem de gordura a ser adicionada no produto processado para obtenção de um produto aceitável do ponto de vista sensorial.

Embutidos fermentados apresentam maiores problemas quando se trata de redução do teor de lipídios, pois este parâmetro é determinado em larga escala pela gordura adicionada (toucinho suíno), cuja função tecnológica é importante. O toucinho contribui para evitar a compactação da massa, estimulando a evaporação contínua, imprescindível a uma boa maturação e aromatização do produto (Wirth, 1991). Embutidos com granulação mais fina seriam os mais adequados para a redução do teor de gorduras. Wirth (1972) afirma que nos embutidos fermentados, tais como "rohwurst", o teor de gordura pode ser reduzido de $30-55$ a $12-15 \%$, porém o teor de gordura adicionado não deve ser menor do que $10 \%$, por razões tecnológicas. Segundo Bacus (1984), é possível produzir salames com $15 \%$ de gordura com quantidades reduzidas de toucinho. A análise destes produtos demonstra que estes atingem $20 \%$ de teor de gordura em duas semanas, e $30 \%$ em quatro semanas, e que os produtos comerciais geralmente possuem de 35 a $55 \%$ de gordura. Deve-se considerar que estes embutidos secam muito mais rapidamente se comparados com produtos com teor normal de gordura, sendo maior a probabilidade de falsa desidratação na superfície (Wirth, 1991).

Vários estudos relatam o efeito da utilização de baixos teores de gordura em embutido fermentados. Acton \& Dick (1975) estudaram o efeito de adição de dois níveis de gordura, $15 \%$ e $30 \%$, nas características químicas, microbiológicas e físicas de embutidos fermentados de carne de peru, e encontraram diferenças na textura dos produtos. Schackelford et al. (1990) avaliaram o processamento e caracterís- ticas sensoriais de embutido fermentado com carne suína contendo $15 \%$ ou $25 \%$ de gordura e vários níveis de ácido oléico. O embutido fermentado com $15 \%$ de gordura apresentou boas características sensoriais. O efeito da incorporação de "surimi" neste tipo de embutido com diferentes níveis de gordura também foi relatado (Cavestany et al., 1994).

O objetivo deste trabalho foi estudar o efeito da adição de diferentes teores de gordura no processamento, características químicas e aceitação sensorial dos embutidos fermentados de carne de caprinos.

\section{Material e Métodos}

Carne de caprinos proveniente de animais adultos, abatidos entre 16 e 18 meses de idade, sem distinção de raça, desossados da carcaça inteira, foi previamente moída em discos de $8 \mathrm{~mm}$ e congelada em freezer a $-18^{\circ} \mathrm{C}$ na forma de camadas finas de, aproximadamente, $2 \mathrm{~cm}$, como preparação para o processamento. Após o congelamento, a carne foi quebrada em pequenos blocos e foi moída em discos de $6 \mathrm{~mm}$, junto de gordura (toucinho suíno). Foram testadas as porcentagens de gordura de $5,10 \mathrm{e} 20 \%$. Os ingredientes foram utilizados na seguinte proporção: sal (2,5\%), mistura comercial para cura $(0,30 \%)$, isoascorbato de sódio $(0,25 \%)$, glicose $(0,50 \%)$, sacarose $(0,50 \%)$, glutamato monossódico $(0,20 \%)$, pimenta-branca $(0,10 \%)$, nozmoscada $(0,10 \%)$ e alho em pó $(0,10 \%)$. Foi utilizada cultura "starter" contendo os microorganismos Staphylococcus xylosus e Pediococcus pentosaceus, na proporção de $0,02 \%$. A carne, gordura e ingredientes foram misturados em misturadeira industrial, e a seguir, as amostras foram embutidas em tripas de colágeno reconstituído, com calibre $45 \mathrm{~mm}$, e depois levadas a uma câmara de umidade relativa e temperatura controladas durante 14 dias. A programação de temperatura e umidade relativa está apresentada na Tabela 1. Foram processadas duas bateladas de $3 \mathrm{~kg}$ de produto por tratamento.

Durante o processamento, foram monitorados os valores de $\mathrm{pH}$ e a atividade da água (Aw), nos dias $0,1,2,7$

Tabela 1. Temperatura e umidade relativa no processamento de embutidos fermentados de carne de caprinos.

\begin{tabular}{lccccc}
\hline Dia de processo & \multicolumn{2}{c}{ Temperatura $\left({ }^{\circ} \mathrm{C}\right)$} & & \multicolumn{2}{c}{ Umidade relativa $(\%)$} \\
\cline { 2 - 3 } \cline { 5 - 6 } & Mínima & Máxima & & Mínima & Máxima \\
\hline $1^{\mathbf{0}}$ & 22 & 23 & & 85 & 95 \\
$2^{\mathbf{o}}$ & 18 & 20 & & 80 & 90 \\
$3^{\mathbf{o}}$ em diante & 12 & 15 & & 70 & 80 \\
\hline
\end{tabular}


e 14. As amostras obtidas ao final do processamento foram analisadas imediatamente após o período de 14 dias, considerada como final de processamento.

Para as análises físico-químicas, foram coletados aleatoriamente três gomos de amostra de cada tratamento, e as análises, realizadas, no mínimo, em triplicata. Os valores de $\mathrm{pH}$ foram obtidos em potenciômetro digital (marca Hanna Instruments, modelo HI 9321), em três repetições. Para análise, as amostras foram diluídas com água destilada, na proporção 1:1 (p:v), e homogeneizadas com bastão de vidro, técnica descrita por Terra \& Brum (1985). Na determinação de atividade de água (Aw), foi utilizado o aparelho marca Decagon Devices Inc., modelo Aqualab CX-2. O teor de umidade foi determinado por perda de peso em estufa a $105^{\circ} \mathrm{C}$, segundo método AOAC 950.46 (Association of Analytical Chemists, 1990). O teor de proteína foi determinado pelo método micro-Kjeldahl, utilizando-se como fator de conversão 6,25, segundo método AOAC 928.08 (Association of Analytical Chemists, 1990). O teor de gordura foi determinado por meio de extração com hexano, com extrator de Sohxlet, segundo método AOAC 960.39 (Association of Analytical Chemists, 1990).

Para análise sensorial, foram coletadas aleatoriamente aproximadamente $30 \mathrm{~g}$ de amostra por repetição. Foi aplicado o teste sensorial de aceitação, utilizando-se escala hedônica estruturada de nove pontos, variando de "desgostei muitíssimo" (nota 1) a "gostei muitíssimo" (nota 9). Utilizaram-se 30 provadores não treinados para avaliação das amostras. As amostras foram entregues aos provadores (aproximadamente $10 \mathrm{~g}$ ), equivalentes a duas fatias de salame, em pratos de plástico branco, codificados com números de três dígitos, acompanhados de um copo de água e um biscoito tipo água e sal, para ser utilizado pelo provador entre as amostras. O número máximo de amostras por sessão para cada provador foi de três, entregues separadamente (apresentação monádica). Foram avaliados a aceitação global e os atributos aparência, aroma, sabor e textura. Para avaliar aparência, aroma, sabor e textura, procedeu-se da seguinte maneira: foi solicitado ao provador que avaliasse primeiramente a aparência de três amostras codificadas, apresentadas em pratos de plástico branco. Em seguida, o provador se dirigiu para a cabine, onde avaliou os outros atributos (Meilgaard et al., 1987).

Os resultados obtidos nas análises físico-químicas e nos testes de aceitação sensorial foram submetidos à análise de variância univariada (ANOVA) e as médias comparadas pelo teste de Tukey a $5 \%$ de probabilidade, por meio do programa estatístico SAS for Windows, versão 6.12.

\section{Resultados e Discussão}

Verificou-se o mesmo comportamento de queda de $\mathrm{pH}$ e Aw, dentro das condições de processamento deste experimento (Figuras $1 \mathrm{e} 2$ ). A amostra com 20\% de gordura, a partir do segundo dia, apresentou mai-

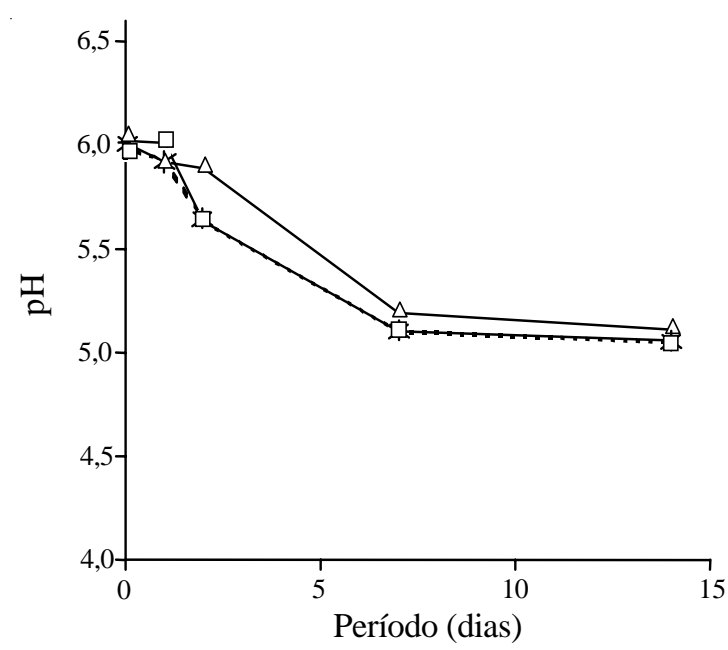

Figura 1. Evolução do $\mathrm{pH}$ dos embutidos fermentados de carne de caprinos formulados com $5 \%(*), 10 \%$ ( $\square)$ e $20 \%(\triangle)$ de gordura, durante o período de processamento.

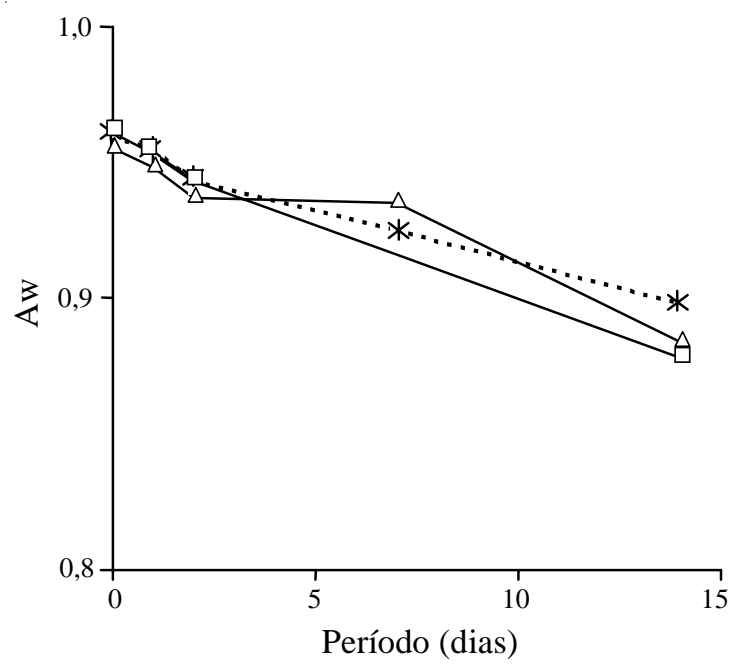

Figura 2. Evolução da atividade da água (Aw) dos embutidos fermentados de carne de caprinos formulados com $5 \%$ (*), $10 \%(\square)$ e $20 \%(\triangle)$ de gordura, durante o período de processamento. 
or valor de $\mathrm{pH}$ do que os outros tratamentos, confirmando, assim, que quanto menor a porcentagem de gordura, mais rápida a queda do $\mathrm{pH}$ (Bacus, 1986). Porém, no final do processamento, os valores das amostras não apresentaram diferença significativa a 5\%, o mesmo ocorrendo com valores de Aw. A porcentagem de perda de peso das amostras foi, em média, de $30 \%$.

Em relação aos valores médios finais de $\mathrm{pH}$ e Aw, não houve diferença significativa $(\mathrm{P}>0,05)$ entre os tratamentos, ou seja, o teor de gordura não influenciou nos valores finais de Aw e $\mathrm{pH}$ dos produtos (Tabela 2). A porcentagem de gordura diferiu entre os tratamentos $(\mathrm{P}<0,05)$, e apresentou-se proporcional à quantidade de gordura adicionada, isto é, aumentou à medida que maior teor de gordura foi adicionado, como esperado. Os valores de umidade não diferiram entre si $(\mathrm{P}>0,05)$, ao passo que se observou diferença entre os teores de proteína (Tabela 2 ).

Não houve diferença significativa $(\mathrm{P}>0,05)$ entre os tratamentos, em relação aos valores de aceitação global, e em relação aos atributos aparência, aroma, sabor e textura (Tabela 3), o que indica que todos os atributos analisados tiveram notas que corresponderam a "não gostei nem desgostei" (nota 5) a "gostei ligeiramente" (nota 6).

Quanto à freqüência das notas obtidas para aceitação global e quanto aos atributos aparência, aroma, sabor e textura, observa-se uma tendência maior de notas acima de 6 (Figura 3). A formulação contendo $20 \%$ de gordura obteve maior porcentagem de notas $6,7,8$ e 9 com relação à aceitação global e ao atributo aparência, e o menor somatório relativo ao atributo aroma. Quanto aos atributos sabor e textu-

Tabela 2. Média final de pH e atividade da água (Aw), e composição química dos embutidos fermentados de carne de caprinos formulados com diferentes teores de gordura $^{(1)}$.

\begin{tabular}{lccc}
\hline Variável & \multicolumn{3}{c}{ Teor de gordura (\%) } \\
\cline { 2 - 4 } & 5 & 10 & 20 \\
\hline pH & $5,05 \mathrm{a}$ & $5,06 \mathrm{a}$ & $5,11 \mathrm{a}$ \\
Aw & $0,898 \mathrm{a}$ & $0,878 \mathrm{a}$ & $0,882 \mathrm{a}$ \\
Umidade (\%) & $49,55 \mathrm{a}$ & $49,03 \mathrm{a}$ & $49,19 \mathrm{a}$ \\
Proteína (\%) & $31,84 \mathrm{a}$ & $26,78 \mathrm{~b}$ & $23,89 \mathrm{c}$ \\
Gordura (\%) & $10,76 \mathrm{c}$ & $15,01 \mathrm{~b}$ & $21,54 \mathrm{a}$ \\
Relação umidade:proteína & 1,6 & 1,8 & 2,1 \\
\hline
\end{tabular}

${ }^{(1)}$ Médias seguidas das mesmas letras na mesma linha não diferem entre si pelo teste de Tukey a 5\% de probabilidade. ra, os somatórios relativos aos tratamentos com 5\% e $20 \%$ de gordura foram similares. Os comentários espontâneos feitos pelos provadores nas fichas de escala hedônica, sobre a textura do produto com $5 \%$ de gordura, foram negativos, com citações como "textura muito firme", "muito duro" e "difícil de mastigar". Estes comentários estão coerentes com o tipo de produto, no qual foi adicionada uma quantidade mínima de gordura; além disso, a carne de caprinos também possui baixo teor de gordura, o que leva a um produto final com a textura muito dura. Segundo Keeton (1994), produtos que têm a porcentagem de

Tabela 3. Valores médios de testes de aceitação sensorial dos embutidos fermentados de carne de caprinos formulados com diferentes teores de gordura $^{(1)}$.

\begin{tabular}{lccc}
\hline Variável & \multicolumn{3}{c}{ Teor de gordura (\%) } \\
\cline { 2 - 4 } & 5 & 10 & 20 \\
\hline Aceitação global & $5,1 \mathrm{a}$ & $5,7 \mathrm{a}$ & $5,0 \mathrm{a}$ \\
Aparência & $5,5 \mathrm{a}$ & $5,1 \mathrm{a}$ & $5,7 \mathrm{a}$ \\
Aroma & $5,3 \mathrm{a}$ & $5,8 \mathrm{a}$ & $5,4 \mathrm{a}$ \\
Sabor & $6,0 \mathrm{a}$ & $6,2 \mathrm{a}$ & $5,7 \mathrm{a}$ \\
Textura & $5,5 \mathrm{a}$ & $5,6 \mathrm{a}$ & $5,2 \mathrm{a}$ \\
\hline
\end{tabular}

(1)Médias seguidas das mesmas letras na mesma linha não diferem entre si pelo teste de Tukey a $5 \%$ de probabilidade.

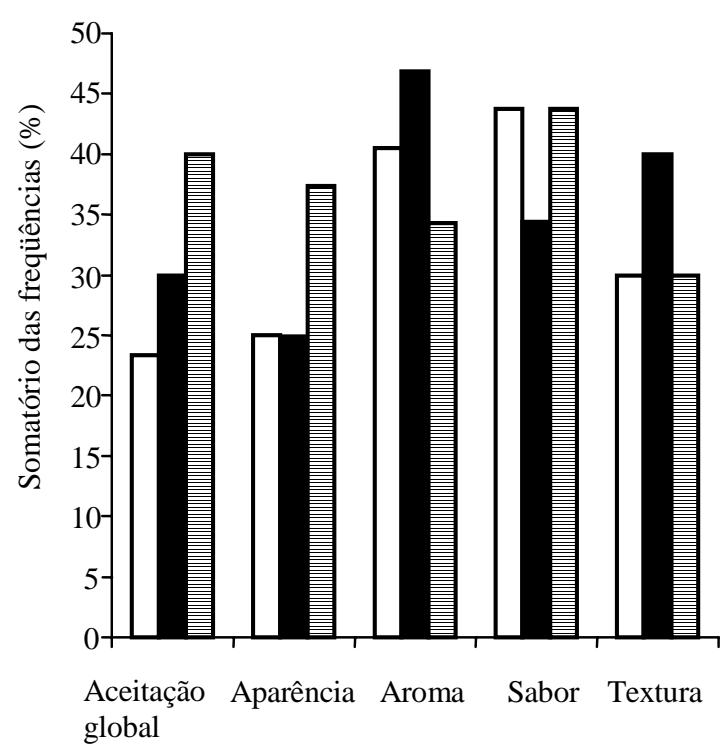

Figura 3. Representação gráfica do somatório das frequiências de notas $6,7,8$ e 9 nos embutidos fermentados de

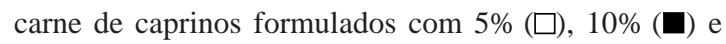
$20 \%(\Xi)$ de gordura. 
gordura reduzida em $10 \%$ da formulação usual resultam em um produto com textura dura, borrachenta ou farinhenta. Nas amostras com $10 \%$ e $20 \%$ de gordura, destacaram-se comentários positivos em relação ao aroma e ao sabor do produto. Com relação ao atributo textura, foram feitos menos comentários negativos sobre a amostra com $10 \%$ de gordura, ao passo que sobre a amostra com $20 \%$ foram observados desagrados em relação à textura "demasiadamente macia”. Segundo Mittal \& Barbut (1994), apesar do conteúdo calórico, a gordura contribui para o sabor, o aroma, a suculência e a textura em muitos produtos. Portanto, qualquer tentativa para reduzir o teor de gordura em alimentos deve levar em consideração a contribuição da gordura nas propriedades organolépticas deste produto. Em produtos cárneos, a gordura é essencial para o sabor, aroma e textura, e sua redução pode afetar a aceitação do produto. Cross et al. (1980), em estudo sobre o efeito de diferentes teores de gordura nas características químicas e sensoriais de produtos reestruturados de carne bovina, relataram que, quanto maior o teor de gordura, maior seria a maciez e suculência dos produtos estudados.

\section{Conclusões}

1. A porcentagem de gordura mais adequada está entre $10 \%$ a $20 \%$ para o embutido fermentado de carne de caprinos.

2. A aceitação sensorial global e a textura do embutido fermentado de carne de caprinos é influenciada pelo teor de gordura adicionado.

\section{Referências}

ACTON, J. C.; DICK, R. L. Improved characteristics for dry, fermented turkey sausage. Food Product Development, Chicago, v. 9, n. 8, p. 91-94, Oct. 1975.

ASSOCIATION OF ANALYTICAL CHEMISTS (Gaithersburg, Estados Unidos). Official methods of analysis. 15. ed. Washington, 1990. 1298 p.

BACUS, J. Update: meat fermentation 1984. Food Technology, Chicago, v. 38, n. 6, p. 59-69, June 1984.

BACUS, J. Utilization of microorganisms in meat processing. Letchworth: Research Studies Press/ J. Wiley, 1986. $170 \mathrm{p}$.
CARBALLO, J.; MOTA, N.; BARRETO, G.; JIMENEZCOLMENERO, F. Binding properties and color of Bologna sausages with varying fat levels, protein levels and cooking temperatures. Meat Science, Essex, v. 41, n. 3, p. 301313, Dec. 1995.

CAVESTANY, M.; JIMENEZ-COLMENERO, F.; SOLAS, M. T.; CARBALLO, J. Incorporation of sardine surimi in Bologna sausage containing different fat levels. Meat Science, Essex, v. 38, n. 1, p. 27-37, Oct. 1994.

CROSS, H. R.; BERRY, B. W.; WELLS, L. H. Effects of fat level and source on the chemical, sensory and cooking properties of ground beef patties. Journal of Food Science, Chicago, v. 45, n. 4, p. 791-793, Apr. 1980.

FOEGEDING, E. A.; RAMSEY, S. R. Effect of gums on low fat meat batters. Journal of Food Science, Chicago, v. 51, n. 1, p. 33-36, 46, Jan. 1986.

KEETON, J. T. Low-fat meat products: technological problems with processing. Meat Science, Essex, v. 36, n. 1/2, p. 261-276, Jan./Feb. 1994.

MEILGAARD, M.; CIVILlE, G. V.; CARR, B. T. Sensory evaluation techniques. Boca Raton: CRC, 1987. v. 2.

MITTAL, G. S.; BARBUT, S. Effects of fat reduction on frankfurters' physical and sensory characteristics. Food Research International, Oxford, v. 27, n. 5, p. 425-431, Sept./Oct. 1994.

SCHACKELFORD, S. D.; MILLER, M. F.; HAYDAN, K. D.; REAGAN, J. O. Evaluation of the physical, chemical and sensory properties of fermented summer sausage made from high-oleate pork. Journal of Food Science, Chicago, v. 55, n. 4, p. 937-941, Apr. 1990.

SOFOS, J. N.; ALLEN, C. E. Effects of lean meat source and levels of fat and soy protein on the properties of viener type products. Journal of Food Science, Chicago, v. 42, n. 4, p. 875-878, Apr. 1977.

TERRA, N. N.; BRUM, M. A. R. Carne e seus derivados: técnicas de controle de qualidade. São Paulo: Nobel, 1985. $121 \mathrm{p}$.

WALLINGFORD, L.; LABUZA, T. P. Evaluation of the water binding properties of food hydrocolloids by physical/ chemical methods in a low fat emulsion. Journal of Food Science, Chicago, v. 48, n. 1, p. 1-5, Jan. 1983.

WIRTH, F. Reducing the fat and sodium content of meat products. What possibilities are there? Fleischwirtschaft, Frankfurt, v. 71, n. 3, p. 294-297, Mar. 1991.

WIRTH, F. The fat content of meat products: technological possibilities of lowering calorie content. Fleischwirtschaft, Frankfurt, v. 52, n. 8, p. 1006-1008, Aug. 1972.

Pesq. agropec. bras., Brasília, v. 37, n. 8, p. 1169-1173, ago. 2002 